\title{
Nitroso Carcinogen
}

National Cancer Institute

\section{Source}

National Cancer Institute. Nitroso Carcinogen. NCI Thesaurus. Code C45181.

A compound with carcinogenic properties that contains an - $\mathrm{NO}$ group. ( $\mathrm{NCI05)}$ 